\title{
Impact of New Design Techniques on Environmental Orientation of Architectural Form-Finding
}

\author{
Romuald Tarczewski \\ Faculty of Architecture, Wroclaw University of Technology, Poland \\ romuald. tarczewski@pwr.wroc.pl
}

\begin{abstract}
The paper presents problems related with influence of new techniques of building modeling on creation of architectural form. Short historical context is presented, which allows reader to became familiar with some oldest issues related to the exchange of information in the investment process. It is followed by study of architect-structural engineer relations and changes caused by new paradigms of aesthetics, referred to as "free-form design".
\end{abstract}

Keywords: free-form modeling, organic forms, spatial structures, shell and spongy structures, 3D modeling.

\section{Introduction}

The Baroque era was a breakthrough in the development of the form in art. Its eccentric redundancy and noisy abundance of details contrasted the clear and sober rationality of the Renaissance and Antiquity. This was reflected also in the architecture. However, technical limitations did not allow the use in buildings equally free-form as, for example, in sculptures. The technological revolution in the construction and design methods has opened new possibilities for shaping architectural forms. In the late nineteenth and early twentieth centuries the process of developing architectural forms appropriate to the new design possibilities was palpably under way. An example of a building whose form became a symbol of change, even against the background of contemporary Art Nouveau style, is Gaudi's Casa Mila.

A hundred years later, the situation appears to be reversed than was previously. There is a need to develop methods of shaping structural systems which not only meet the challenges posed by new forms of geometry but are a source of inspiration for the creation of new forms. A set of trends, often referred to collectively as 'free-form design' established a new paradigm of aesthetics in architectural design. Designers use means of expression such as: large span, organic forms, randomness, discontinuity of the structural system. These trends developed on the basis of new methods of computer generation of geometric forms. Such tools give designers almost unlimited freedom to create and change to some extent a way of thinking, free from the orthogonal preferences associated with the use of traditional drawing boards. 


\section{The Investment Process as the Process of Generation and Exchange of Information}

When a man, sheltering from the weather conditions went from the initial phase of search for a refuge in natural places and the construction of primitive huts, to the phase of construction of objects that can be called (according to our present terminology) houses - construction as one of the important areas of human activity was born. Then appeared specialized craftsmen engaged in building not only for their own purposes, but primarily for the needs of others. Almost immediately, appeared the problem, which we would call today "the modeling of building objects". The investor had to clearly communicate his expectations to contractor, so that he could build an object corresponding to the contract. It was also important in order to set the price for the work.

\subsection{Building Modeling from Antiquity to the Renaissance}

As long as the activity concerned common, well-known and accepted technologies and solutions, "model" of the building could be very simple. A simple residential building could be described simply by the amount of chambers. In the case of the palace and sacred buildings, more complex descriptions were used, including drawings.

Building modeling dates back to ancient Mesopotamia. It is represented: “... with examples of building specific documentation across a broad spectrum of types: existing plans, plans and elevations, models, quantities, contracts for supply, reports of work-in-progress, workshop records, metrological texts, dedicatory inscriptions and contracts for sale of buildings" [4]. Construction and information technologies of the time were clay-based - about five thousands of clay tablets of this type have been excavated. Until today survived around 30 tablets with floor plans of buildings, houses, temples and ziggurats. The tablets have plans of elevations, combined planelevations and annotation. Some of the plans give dimensions, and some give room names. "Many tablets show walls as a pair of parallel lines, with doorways shown as a break in the wall. Some show walls as single lines, with openings marked by strokes across the lines" [4].

The text descriptions, especially bills of quantities, were one of the most important documents describing the building. Their importance is largely the result of the fact that they allowed to estimate the cost of construction of the building. Ancient Mesopotamians developed a series of standard coefficients to convert floor areas to the number of bricks, depending on the size of the brick. Among the oldest documents for the construction of the building is bill of quantities for the Greek fleet arsenal in Piraeus, dating from about 300 years BC [10]. Use of the building models, both descriptions and drawings, allowed to link the agreement between craftsmen and investors with current legal system. The Code of Hammurabi provided a very severe punishment, including decapitation, for the perpetrator of construction disaster. Vitruvius, in the introduction to the tenth chapter of his book De Architectura libri decem, 
describes the customs in Ephesus, regarding reward and punishment of architects who kept or exceeded the planned investment costs.

It is not difficult to see that most of the buildings, which originated in ancient times disclose largely orthogonal preferences. They are just the result of modeling of buildings. Both the transmission of information between the contractor and the investor, and the modeling of the structural system, allowed operating only a limited number of means of expression. Since the design methods of complex structural systems were unknown - mostly simple, pole-beam structures were constructed. A development occurred in Roman times, when arches and vaults began to be commonly used. The Hypostyle Hall of the Temple of Amun in Karnak, Egypt is a good example of this approach.

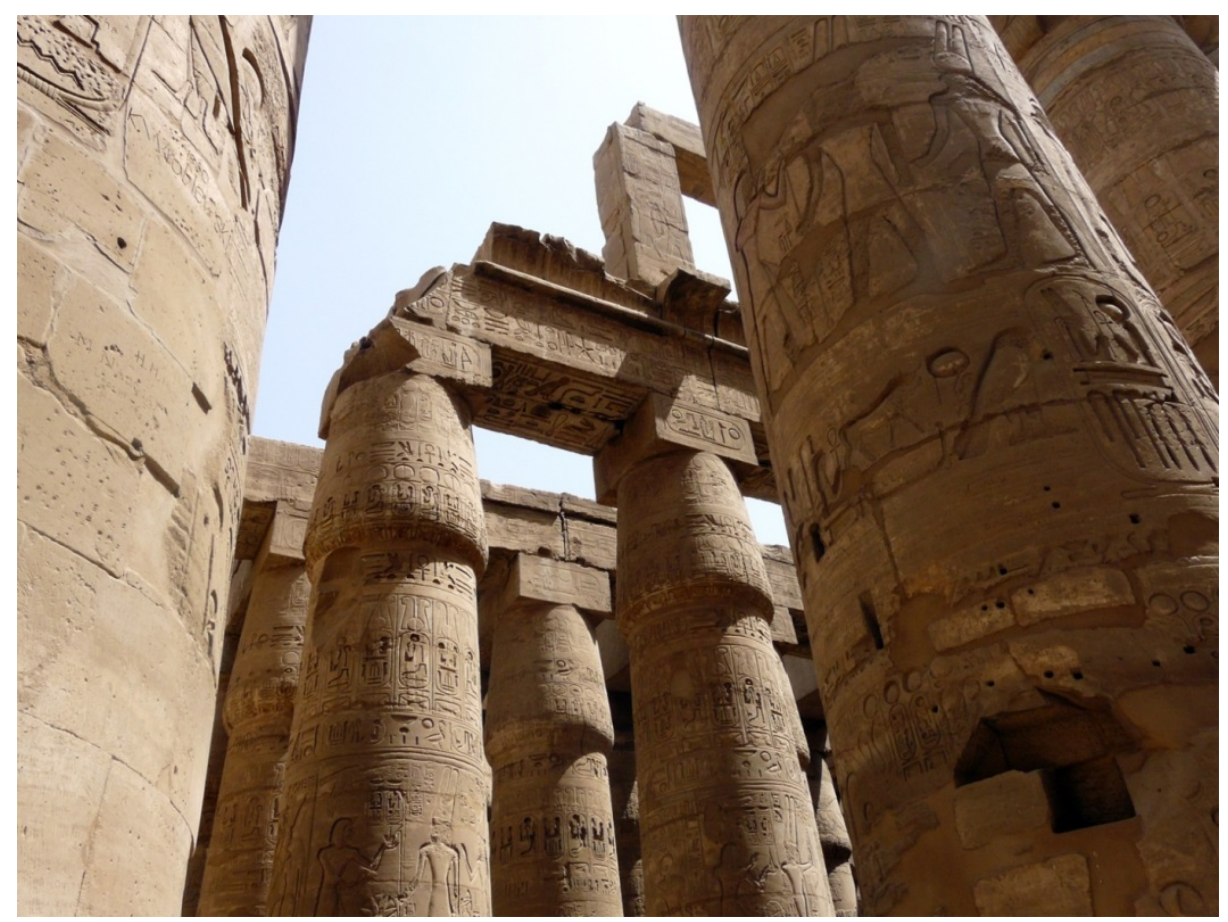

Fig. 1. Hypostyle Hall, Temple of Amun, Karnak, Egypt (photo: Wikimedia, CC license)

\subsection{Modeling of Buildings in Modern Times}

The term technology of information exchange includes both its physical media, and concepts of the its producing, notation and presentation. Progress in this area took place continuously throughout the centuries, but rapidly accelerated since the Renaissance. Table 1 presents a comparison of the periods of emergence and use of the key information exchange techniques. 
Table 1. Evolution of techniques of information exchange in the investment process [3]

\begin{tabular}{|c|c|c|c|c|c|c|c|c|c|c|}
\hline Century & 13 & 14 & 15 & 16 & 17 & 18 & 19 & $\begin{array}{c}\text { to } \\
1950\end{array}$ & $\begin{array}{c}\text { to } \\
2000\end{array}$ & $\begin{array}{l}\text { beyond } \\
2000\end{array}$ \\
\hline \multicolumn{11}{|l|}{ Parchment } \\
\hline \multicolumn{11}{|l|}{ Abacus } \\
\hline \multicolumn{11}{|l|}{ Arabic numerals } \\
\hline \multicolumn{11}{|l|}{ Cotton-based paper } \\
\hline \multicolumn{11}{|l|}{ Spectacles } \\
\hline \multicolumn{11}{|l|}{ Standardized imperial measurement } \\
\hline \multicolumn{11}{|l|}{ Perspective } \\
\hline \multicolumn{11}{|l|}{ Orthographic triad to same scale } \\
\hline \multicolumn{11}{|l|}{ Modern drawing instruments } \\
\hline \multicolumn{11}{|l|}{ Printing press } \\
\hline \multicolumn{11}{|l|}{ Movable type } \\
\hline \multicolumn{11}{|l|}{ Graphite pencils } \\
\hline \multicolumn{11}{|l|}{ Graduated rules } \\
\hline \multicolumn{11}{|l|}{ Linen-based paper } \\
\hline \multicolumn{11}{|l|}{ Pattern books } \\
\hline \multicolumn{11}{|l|}{ Metric measurement } \\
\hline \multicolumn{11}{|l|}{ Modern 'lead' pencils } \\
\hline \multicolumn{11}{|l|}{ Wood-based paper } \\
\hline \multicolumn{11}{|l|}{ Colour pencils } \\
\hline \multicolumn{11}{|l|}{ Tracing paper } \\
\hline \multicolumn{11}{|l|}{ Reliable drawing boards } \\
\hline \multicolumn{11}{|l|}{ Tee squares } \\
\hline \multicolumn{11}{|l|}{ Published standards } \\
\hline \multicolumn{11}{|l|}{ Typewriter } \\
\hline \multicolumn{11}{|l|}{ Mimeography } \\
\hline \multicolumn{11}{|l|}{ Blueprints } \\
\hline \multicolumn{11}{|l|}{ Photocopiers } \\
\hline Technical pens & & & & & & & & & & \\
\hline Felt-tip pens & & & & & & & & & & \\
\hline Polymer pencils & & & & & & & & & & \\
\hline Plastic paper & & & & & & & & & & \\
\hline Computers & & & & & & & & & & \\
\hline Adult literacy & & $2.5 \%$ & & & & & & $5 \%$ & & \\
\hline
\end{tabular}

There can be identified several milestones in the formation of the conventions for the representation of architectural works and projects. The sketchbook of Villard de Honnecourt on parchment (1230-35) and the plan of the Abbey of Saint Gallen $(\sim 820)$ show the roots of modern architectural representation. Others are: invention of 
perspective by Brunelleschi ( 1410), introduction of Modern "lead" pencils by N.-J. Conté (1795), W.F. Stanley's invention of tee squares (1860) and reliable drawing boards (1870), introduction of technical pens (1932) and invention of felt-tip pens by Rotring (1952). The recent revolutionary step in this way was the introduction of computers into the common use, in the eighties of the twentieth century. An idea of the scale of these changes gives a comparison of drawing instruments from the sixteenth and eighteenth centuries, Fig. 2.

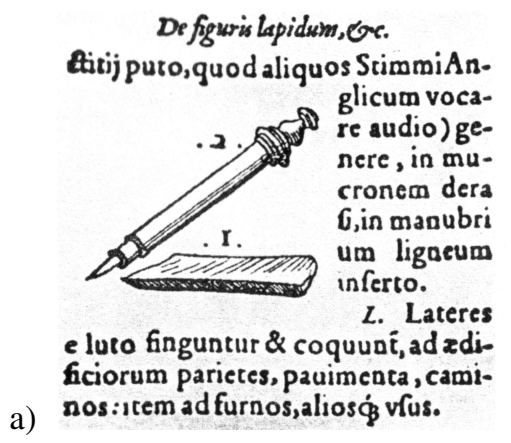

b)

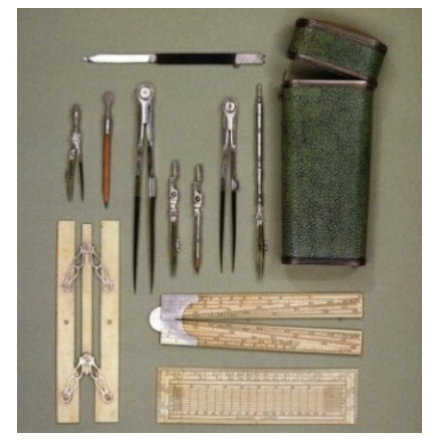

Fig. 2. The old drawing instruments: a) the oldest known drawing of a pencil (1565) and b) draftsman's pocket toolbox (1782) [5]

Major changes covered also the structural design. Starting from the seventeenth century are developing new areas of knowledge: structural mechanics and strength of materials. It became possible to use structural systems much more complex and achieve far greater values of parameters such as the span and height. Structures have become considerably lighter in comparison with those of the previous periods - example on Figure 3. After World War II, appeared a new method of calculating structures that dominated the structural design: Finite Element Method. Its uniform, universal approach to solving various problems has provided designers with completely new, previously unavailable capabilities.

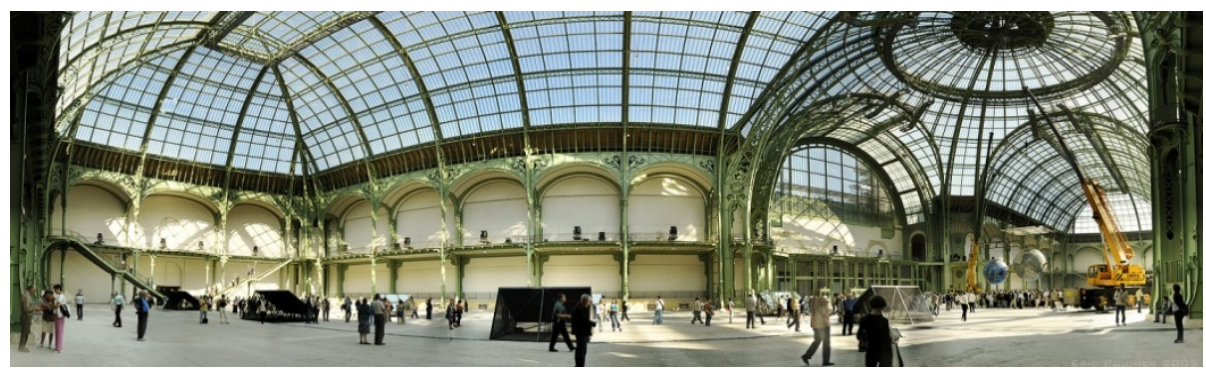

Fig. 3. Grand Palais, Paris (photo: Wikimedia, CC license)

In this way, a new building modeling techniques have opened for designers a new window of opportunity. The problem is now not just the design of a particular form but to find new and original one. 


\section{New Paradigms of Aesthetics}

In 1915 American architect, Claude Bragdon, noted that: "modern architecture, except on its engineering side, has not yet found itself: the style of a building is determined, not by necessity, but by the whim of the designer; it is made up of borrowings and survivals". The author of these words added that "the development of new architectural forms appropriate to the new structural methods is already under way, and its successful issue may safely be left to necessity and to time" [1].

After a hundred years that have passed since this statement, the situation seems to be reversed. There is a need to develop such methods of formulation of structural systems, which not only "keep up" for the challenges posed by new forms of geometry, but they will be able to be a source of inspiration for the creation of new forms.

\subsection{Free-Form Design}

The advent of computers has not produced at once great changes in architectural design. A breakthrough was made when the advanced software has allowed relatively easy use of the so-called "new geometries". Many architects have gone into raptures with new design tools. They began to design forms that could not been previously possible to define - available modeling techniques did not allow for it. Thus was born the group trends in architectural design often referred to as "free-form design". It established a new paradigm of aesthetics in architectural design. Designers use means of expression such as: large span, organic forms, randomness, discontinuity of the structural system. These trends developed on the basis of new methods of computer generation of geometric forms. Such tools give designers almost unlimited freedom to create and change to some extent a way of thinking, free from the orthogonal preferences associated with the use of traditional drawing boards. An example is the use of flexible surfaces defined by several control points - NURBS. This approach also allows the use of techniques that are seemingly far from the architectural modeling, known for example of in movie animation. An example would be the use of Autodesk Nucleus module that allows simulation the movement of soft objects. Assuming a flat surface fabric with the desired properties, and then leaving it for a few placed below rigid spheres of different diameter, one can obtain a new, smoothly curved surface. Similar surface has been applied for shaping concrete roof shell in Kakamigahara Crematorium in Japan, designed by Toyo Ito and Mutsuro Sasaki, Fig. 4.

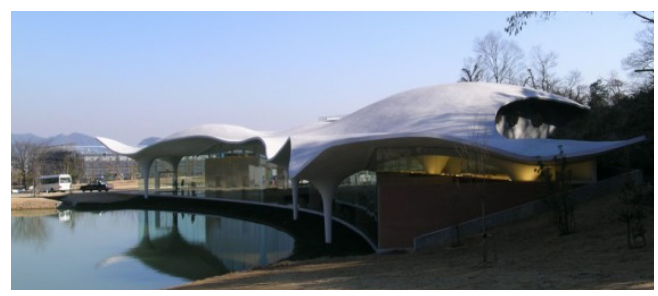

Fig. 4. Kakamigahara Crematorium by Toyo Ito [9] 


\subsection{Reintegration of Architectural Form and Structural System}

These trends were initially contested by structural engineers. Indeed, these geometrical forms could be difficult to achieve with structures of a simple static schemes. This led to the inevitable tensions in relations between architect and engineer and often caused need to enter the far-reaching changes to the original idea. Today, many engineers began to see in the use of new techniques of designing a chance to introduce qualitative changes in the development of structural systems. This is a completely new concept not only in technical solutions but also in the organization of design. The architectural form can no longer be formed independently of the structural design, which is "added" to it later. Its development is the simultaneous exploration of aesthetic expression and the efficiency of the structural system, on a common geometrical base.

So far, it was possible to adapt structural solutions developed over the centuries to the new aesthetic criteria. But now, forms so different from previously used arise, that the current understanding of the logic of structural system becomes useless. An example is the Taichung Metropolitan Opera located in Taiwan, designed by Toyo Ito. This project uses a plurality of curved surfaces, catenoids stretched on cuboidal net of vertices, that passing smoothly into one another, both in the vertical direction and in the horizontal, creating an unusual form of the object, Fig.5. One should also mention the Tandanor Performing Arts Center located at Buenos Aires waterfront, designed by Monad Studio as a composition of sweeping forms and intricate spatial trajectories.

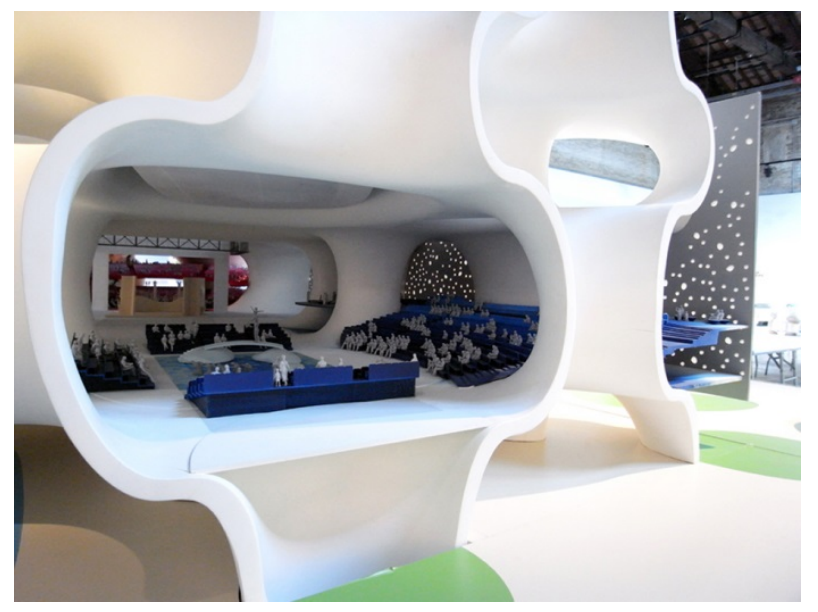

Fig. 5. Taichung Metropolitan Opera in Taiwan, arch. Toyo Ito [11]

This type of buildings commonly referred to as "organic" must be designed as a whole, without separation of structural system design and architectural "rest". Taichung Opera is a wonderful example of this unity.

Similar design recently appeared also as a MSc Diploma project at Faculty of Architecture, Wroclaw University of Technology [8]. This is W. Tunikowski's MoS (Museum of Sexuality) in the estuary of life. 
The building was designed to be a bit shapeless embryo-like structure. Located on the bay, close to the historic monastery of Mont Saint-Michel, is surrounded and periodically flooded by high tide waters of the sea, Fig. 6.

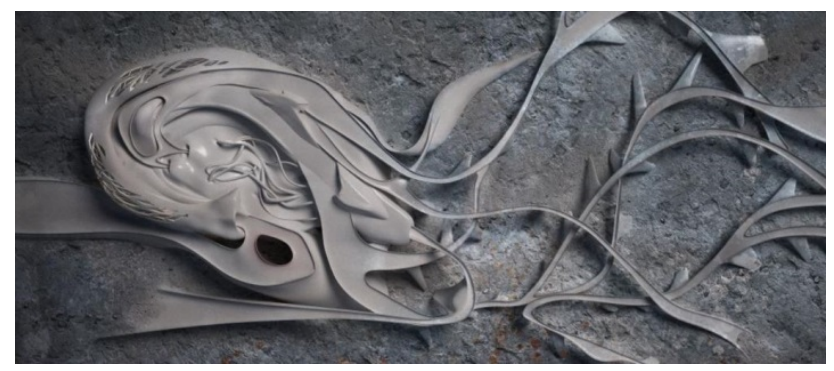

Fig. 6. MoS (Museum of Sexuality) in the estuary of life - general view

The unity of architectural form and structural system is even more evident here than in the case of Taichung Opera House. The branches - "tentacles" of the main body are used not only for creation of additional space, but are also main elements of the building anchorage in the ground, Figure 7. Author claims that the building "creates urbanistic space of cult connected with search of human's existential identity". Adopting this type of aesthetics by young designers who are just starting their career, proves that it is a trend, the glory days of which are yet to come.

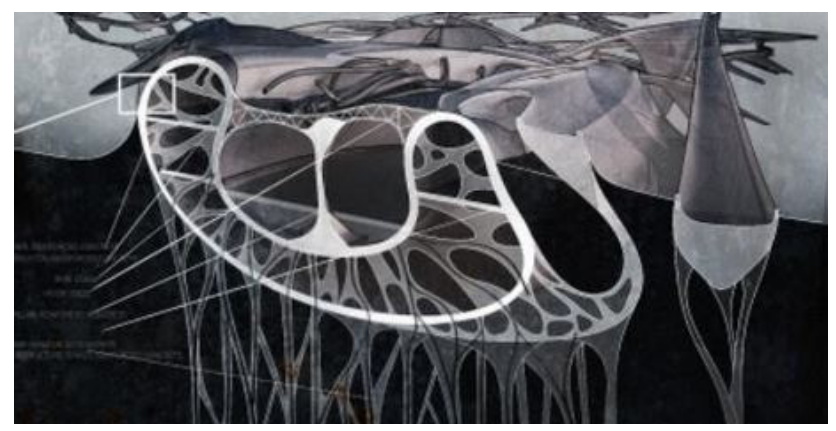

Fig. 7. Mos (Museum of Sexuality) in the estuary of life - section

In the architectural design of such forms, two sources of inspiration are used: natural and geometric, or rather topological. Both are related to the evaluation of the structural properties of achieved forms. In the forms inspired by the natural sources it is possible to direct conclude about the structural properties on the basis of observation of the analyzed objects. In the case of geometrical forms there are the tools that allow assessing and prediction of their properties. 


\section{Geometrical and Structural Basis for Organic Forms}

Geometrical basis for organic forms is provided by the theory of polyhedra, especially saddle polyhedra. The first mathematical attempt to these structures was done in 1890 by H.A. Schwartz. He developed theory of "triply periodic minimal surfaces". The next step was made by H.S.M. Coxeter in thirties last century, who discovered infinite regular polyhedra, and then by A.H. Schoen and M. Burt in sixties - who worked over saddle polyhedra and infinite saddle polyhedra. Such polyhedral compounds are called 'sponges' or 'labyrinths'.

Another inspiration comes from nonorientable closed surfaces with Euler characteristic $\chi=0$. From the large family of geometrical realizations of this abstract (topological) object, immersed in $\mathbb{R} 3$, one can focus his attention on the original geometric construction called Klein bottle. Further continuation of this idea leads to the real projective plane. This is a large group of objects, such as Steiner's roman surface or Boy's surface, which are characterized by a variety of forms that can be used in shaping architectural forms.

Overview of geometric methods shaping organic forms and natural prototypes of structural forms can be found in $[6,7]$.

Structural properties of organic forms i.e. forms based on infinite saddle polyhedra comes from their connection with minimal surfaces. Rigidity of double curved surfaces spanned on non-trivial contour (contour which cannot be immersed in a planar surface in $\mathbb{R} 2$ ) is related to their Gaussian curvature. It applies also to stress distribution. For any closed edge curve there is at least one stable minimal surface. However, there can exist more of these surfaces, provided that they satisfy the Euler-Lagrange equation. Their shape is inter alia result of the external conditions of the medium in which they are located (e.g. loads) and state of stress in them. In the Nature it enables a self-optimization of structures by maintaining a constant state of stress on the surface of a biological component. In the case of engineering structures, constant stress condition cannot be fulfilled for all possible load cases. Thus, structural shaping of such structures becomes interaction of architectural and optimization factors.

A systematic description of a large number of topological objects that may occur in space, and their expected properties and then application to the creation of structural forms, became possible by their systematization in the periodic table, similar to Mendeleev table used in the chemistry. This systematization was proposed by M. Burt in [2]. It is based on statistical characteristics, such as average valency, average sum of angles and genus. These simple characteristics combined with general relations, first of all - Euler's formula, allows not only description of the "polyhedral world" in the currently known extents, but also prediction of new forms, that are of importance for structural shaping.

The close relation between polyhedral geometry and its structural properties has been studied, on the basis of periodic table of polyhedra, in [9]. Figure 8 presents distribution of structural properties due to the potential stability of infinite polyhedra for genus $g=0$ and $g=3$. It includes two types of structures: lattice structures, where edges of the polyhedra are materialized as bars, pin connected in vertices (without 
filling of faces), and plate structures, where faces are realized as plate elements, hinge connected along edges. There are four distinct zones:

zone $\mathrm{A}$ - hiperstable lattice and plate structures

zone B - unstable lattice structures and hiperstable plate structures

zone $\mathrm{C}$ - unstable plate structures and hiperstable lattice structures

zone D - unstable lattice and plate structures

Hiperstability and unstability is here referred to as the number of the edges of polyhedra higher/lower than resultiong from Möbius/Maxwell equations. It may be noted that the border polyhedra between areas A and D are self-dual polyhedra. For genus $g=0$ it is a polyhedron $3^{3}$ - tetrahderon. Based on the graph in Figure 8, one can specify to what extent it is possible to apply bar structures, and to what extent plate or mixed structures.

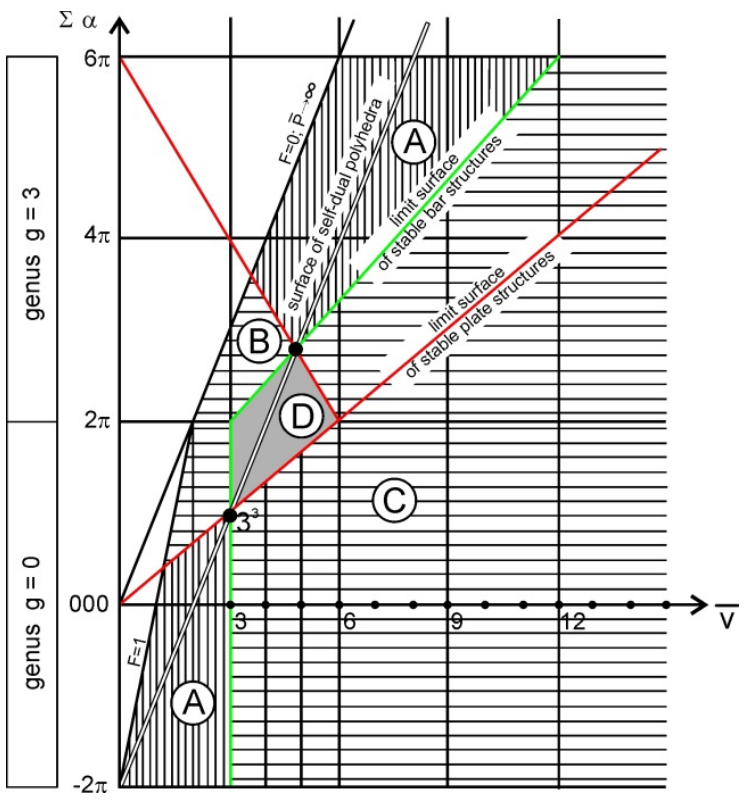

Fig. 8. Distribution of structural properties in relation to potential stability of polyhedra, for genus $\mathrm{g}=0$ and $\mathrm{g}=3$

\section{$5 \quad$ Final Remarks}

This paper focuses only on the aesthetic and structural aspects of the creation of architectural forms. Of course the environmental compatibility of buildings covers a much wider range of issues. However, the two mentioned above are particularly important because of the public perception of architecture.

Modeling of buildings is a specific, problem-oriented way of their presentation. Models are created e.g. for architectural and structural design. They differ substantially from each other and contain different sets of information. Models can be created 
for different purposes, for example for the preparation of financial analyzes, the building management or for exchanging information between the participants of the investment process. Unfortunately, despite the efforts of many companies and institutions, despite the many international programs undertaken, has still not been possible to develop a single, coherent way of modeling which would allow using such model in all necessary aspects and applications. Limitations in modeling capabilities fundamentally affect the created objects in every respect.

As conclusion it should be emphasized, that all new non-traditional design strategies open new window of possibilities for both architectural and structural form finding. Initially the freedom to determine the geometry threatened with a dangerous thoughtlessness and carelessness. Today it is an inspiring challenge. It is difficult at this moment to predict all the consequences of this, but it seems that dominate rather the positives. After a long period of imitations and not very successful postmodern exploration, there is a chance for a real breakthrough.

The new paradigm of aesthetic blurs the differences between the structure and the purely architectural filling. Similarly, should be approached to seek new forms - by combining aspects of design, structural performance and aesthetic. The results of these studies can be obviously different. The mere use of complex, previously impossible to model, forms - does not guarantee a positive aesthetic effect.
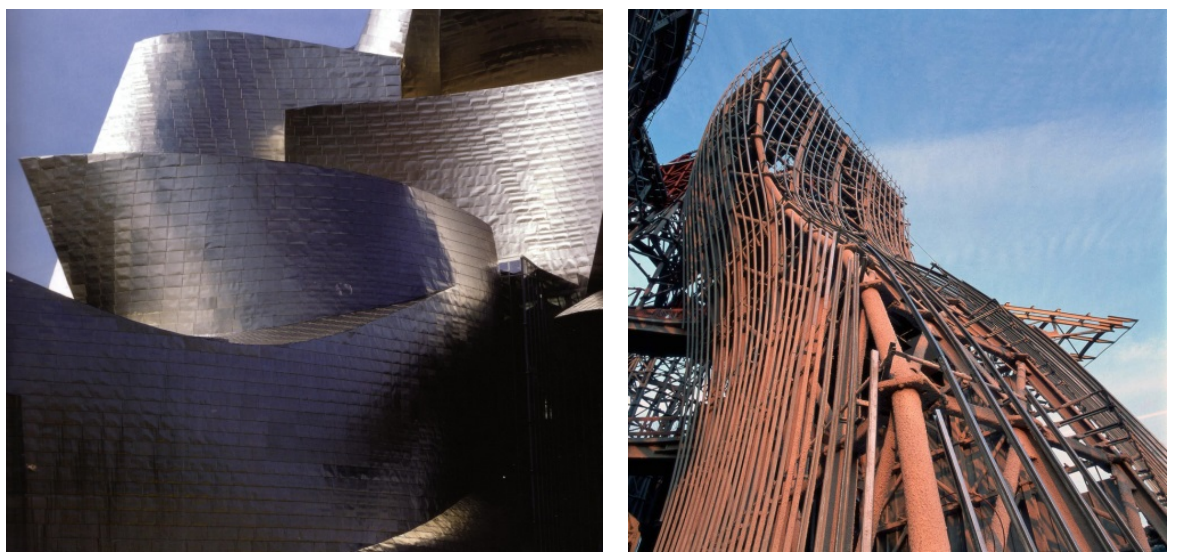

Fig. 9. Guggenheim Museum in Bilbao: a) façade [12], b) structural system [13]

Shown above in Figure 9, the Guggenheim Museum in Bilbao designed by Frank Gehry, impresses with its complex form. At the time it was built, it was a kind of "shock" for modern architecture. But, can this form be considered as environmentally compatible? How much more one can say it about the objects whose form is much simpler, but at the same time remarkable and perfectly complementary to their natural surroundings, such as shown in Figure 10: Oceanarium in Valencia designed by Félix Candela and Salginatobel Bridge designed by Robert Maillart.

Environmental orientation of architectural design has many aspects: energy, climate, etc. This paper focuses on the form-finding. The reasonable use of innovative organic forms, fully integrated with the structural system, is - according to the author - a deep meaning for environmental compatibility of the buildings. 

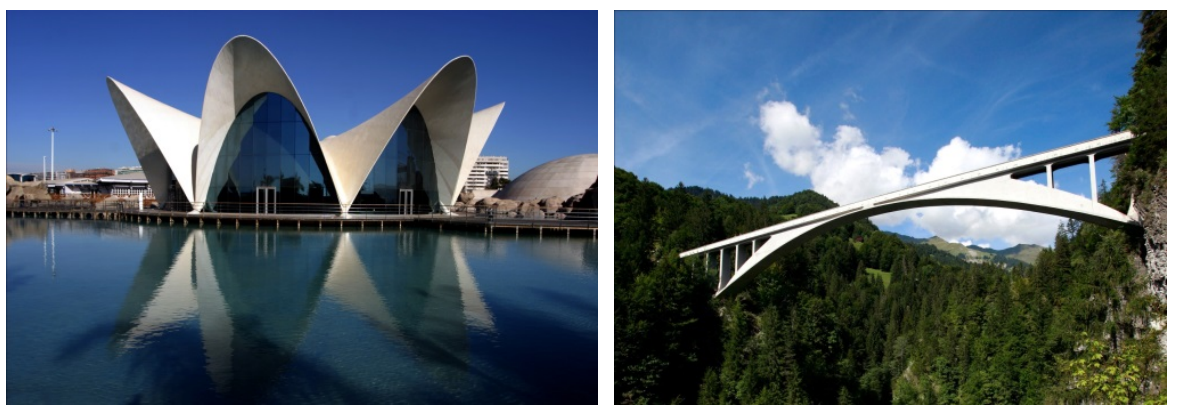

Fig. 10. Two positive examples of environmentally compatible structures: a) Oceanarium in Valencia [14] b) Salginatobel Bridge [15]

Acknowledgements. Author wishes to thank arch. Wojciech Tunikowski for making available drawings from his diploma thesis [3].

\section{References}

1. Bragdon, C.: Projective Ornament. The Manas Press, Rochester (1915)

2. Burt, M.: The periodic table of the polyhedral universe. Technion, Haifa (1996)

3. Gelder, J.: Specifying architecture: a guide to professional practice. Construction Information Systems, Australia (2001)

4. Gelder, J.: Building project documentation in ancient Mesopotamia. Forum 5/1 (September 2002)

5. Hambly, M.: Drawing Instruments, 1580-1980. Sotheby’s Publications, London (1988)

6. Tarczewski, R.: Topology of structural forms. Natural and man-made prototypes of structural forms. Oficyna Wydawnicza Politechniki Wrocławskiej (2011) (in Polish)

7. Tarczewski, R.: Natural and geometrical prototypes of organic forms in architecture. In: Obrębski, J.B., Tarczewski, R. (eds.) Beyond the Limits of Man. Proceedings of the IASS 2013 Symposium, Wrocław, Poland, September 23-27 (2013)

8. Tunikowski W.: MoS (Museum of Sexuality) in the estuary of life. MSc Thesis at the Faculty of Architecture, Wroclaw University of Technology (Nominee to the RIBA President's Medals Student Awards), Wroclaw (2012)

9. Wester, T., Burt, M.: The Basic Structural Content of the Polyhedral Universe and the Plate-Lattice Duality. In: Proceedings of the IASS Symposium on Shell and Spatial Structures, Singapore, vol. 1, pp. 187-196 (1997)

10. Ziolko, J.: Byggesaksdokumenter. Norske standarder og bruk av EDB-methoder. Universitetsforlaget, Oslo (1991)

11. http://www.toyo-ito.co.jp

12. http://www.guggenheim-bilbao.es/en/the-building/

13. http://www.guggenheim-bilbao.es/en/the-building/ the-construction/

14. http://en.wikipedia.org/wiki/File:Valencia_Oceanografic.jpg

15. http://en.wikipedia.org/wiki/ File:Salginatobel_Bridge_mg_4080.jpg 